OPEN ACCESS

Edited by:

Osmano Oasi,

Catholic University of the Sacred

Heart, Italy

Reviewed by:

Francesca Morganti,

University of Bergamo, Italy

Rossella Procaccia,

E-Camus University, Italy

*Correspondence:

Chiara Squarza

chiara.squarza@mangiagalli.it

Specialty section:

This article was submitted to Psychology for Clinical Settings,

a section of the journal

Frontiers in Psychology

Received: 17 February 2016 Accepted: 17 June 2016

Published: 28 June 2016

Citation:

Squarza C, Picciolini O, Gardon L,

Giannì ML, Murru A, Gangi S, Cortinovis I, Milani S and Mosca F

(2016) Learning Disabilities in

Extremely Low Birth Weight Children and Neurodevelopmental Profiles at

Preschool Age. Front. Psychol. 7:998.

doi: 10.3389/fpsyg.2016.00998

\section{Learning Disabilities in Extremely Low Birth Weight Children and Neurodevelopmental Profiles at Preschool Age}

\author{
Chiara Squarza ${ }^{1 *}$, Odoardo Picciolini ${ }^{1}$, Laura Gardon ${ }^{1}$, Maria L. Giannì ${ }^{1}$, \\ Alessandra Murru ${ }^{1}$, Silvana Gangi ${ }^{1}$, Ivan Cortinovis ${ }^{2}$, Silvano Milani ${ }^{2}$ and Fabio Mosca ${ }^{1}$ \\ ' NICU, Department of Clinical Sciences and Community Health, Fondazione IRCCS Ca' Granda Ospedale Maggiore \\ Policlinico, Università degli Studi di Milano, Milan, Italy, ${ }^{2}$ Laboratory of Medical Statistics, Biometry and Epidemiology, \\ Department of Clinical Sciences and Community Health, Università degli Studi di Milano, Milan, Italy
}

At school age extremely low birth weight (ELBW) and extremely low gestational age (ELGAN) children are more likely to show Learning Disabilities (LDs) and difficulties in emotional regulation. The aim of this study was to investigate the incidence of LDs at school age and to detect neurodevelopmental indicators of risk for LDs at preschool ages in a cohort of ELBW/ELGAN children with broadly average intelligence. All consecutively newborns 2001-2006 admitted to the same Institution entered the study. Inclusion criteria were BW $<1000 \mathrm{~g}$ and/or GA $<28$ weeks. Exclusion criteria were severe cerebral injuries, neurosensory disabilities, genetic abnormalities, and/or a Developmental Quotient below normal limits ( $<1 \mathrm{SD})$ at 6 years. The presence of learning disabilities at school age was investigated through a parent-report questionnaire at children's age range 9-10 years. Neurodevelopmental profiles were assessed through the Griffiths Mental Development Scales at 1 and 2 years of corrected age and at $3,4,5$, and 6 years of chronological age and were analyzed comparing two groups of children: those with LDs and those without. At school age 24 on 102 (23.5\%) of our ELBW/ELGAN children met criteria for LDs in one or more areas, with $70.8 \%$ comorbidity with emotional/attention difficulties. Children with LDs scored significantly lower in the Griffiths Locomotor and Language subscales at 2 years of corrected age and in the Personal-social, Performance and Practical Reasoning subscales at 5 years of chronological age. Our findings suggest that, among the early developmental indicators of adverse school outcome, there is a poor motor experimentation, language delay, and personal-social immaturity. Cognitive rigidity and poor ability to manage practical situations also affect academic attainment. Timely detection of these early indicators of risk is crucial to assist the transition to school.

Keywords: extremely low birth weight, Griffiths scales, neurodevelopmental profile, learning disabilities, school outcome 


\section{INTRODUCTION}

Survival rates of preterm infants, especially with extremely low birth weight (ELBW) and/or extremely low gestational age at birth (ELBW and/or ELGAN, respectively), have steadily increased in the last decades due to the improvement of medical knowledge and techniques used in intensive care (Doyle et al., 2011; Latini et al., 2013). As a consequence, the incidence of major sequelae has decreased whereas an increased risk of minor neurobehavioral and cognitive long-term deficits has been reported (Marlow et al., 2005).

Studies on the neuropsychological outcome in ELBW/ELGAN children have disclosed impairments across a wide range of areas, including planning and organization, self-regulation, mental flexibility, and deployment of attention (Farooqi et al., 2013). Difficulties in these areas have been demonstrated to be strongly associated with academic struggles and higher rates of special education support (Msall, 2012).

Consequently, at school age ELBW and/or ELGAN children are more likely to show poorer academic performance than their peers (Litt et al., 2012; Simms et al., 2013). In addition, several authors have found a high rate of Learning Disabilities (LDs) and difficulties in emotional regulation in very and extremely preterm children (Aarnoudse-Moens et al., 2009; Taylor et al., 2011; Lobo and Galloway, 2013). Even ELBW children with IQ scores within broadly normal limits frequently experience difficulties in academic achievement and attention (Grunau et al., 2002).

The identification of early developmental markers that may be predictive of school outcome is essential to provide timely interventions and improve cognitive abilities (Orton et al., 2009). While most studies have investigated neonatal factors that may predict long term school outcomes (Johnson et al., 2011), few have focused on the association between early neurodevelopmental markers that can be identified using the assessment tools commonly administered in clinical and research practice and learning difficulties at school age. Indeed, the general quotients obtained at 2 and 3 years of age with the Griffiths Mental Development Scales were found to strongly correlate with intellectual ability at 5 years assessed by the Stanford Binet in a cohort of ELBW infants (Bowen et al., 1996) and moderately correlate with the Wechsler Preschool and Primary Scale for Intelligence-Revised (WPPSI-R) in a study including infants born at term and with normal birth-weight (Sutcliffe et al., 2010).

The aim of this study was to investigate the incidence of LDs at school age (age range: 9-10 years) in a cohort of children born with ELBW and/or ELGAN with broadly average intelligence and to analyse their neurodevelopmental profiles at preschool age, in order to identify early indicators of risk for adverse school outcomes. Secondly, the prevalence of attention and/or emotional difficulties at school age was explored.

Abbreviations: AGA/SGA, Adequate/Small for Gestational Age; BPD, Bronchopulmonary dysplasia; ELBW, Extremely Low Birth Weight; ELGAN, Extremely Low Gestational Age Newborns; IVH, Intraventricular hemorrhage; LD, Learning disability; NEC, Necrotizing enterocolitis; PVL, Periventricular leukomalacia; ROP, Retinopathy of prematurity.

\section{MATERIALS AND METHODS}

\section{Study Design and Participants}

We performed a single-center longitudinal cohort study. The study was approved by the Ethics Committee of the Fondazione IRCCS Ca' Granda Ospedale Maggiore Policlinico and written informed consent was obtained from all parents.

Inclusion criteria were having a birth weight between 401 and $1000 \mathrm{~g}$ at birth (ELBW) and/or being born between 22 and $27^{+6}$ weeks gestation (ELGAN). Exclusion criteria were the presence of severe cerebral injuries [defined as intraventricular hemorrhage (IVH) grade 3-4 and/or periventricular lekomalacia (PVL) grade 2-4], neurosensory disabilities (blindness, deafness), genetic abnormalities and/or a Developmental Quotient assessed using the Griffiths Mental Development Scales Extended Revised (GMDS-ER) below normal limits (General Quotient $<1$ SD) at 6 years.

The flow chart of the study is shown in Figure 1. Of all the 249 ELBW and/or ELGAN infants admitted to NICU Fondazione IRCCS Ca' Granda Ospedale Maggiore Policlinico, between 2001 and 2006, 214 (85.9\%) were discharged home alive and enrolled in the Follow-up program provided by the Authors' Institution. Of these, $122(57.0 \%)$ returned for the 6 years follow-up visit and $102(47.7 \%)$ entered the study.

\section{Procedure}

Infants were enrolled at 1 year of corrected age and were prospectively followed up to age of 9-10 years. On the basis of the school outcome, children were divided into two groups: those with a LD diagnosis (LD-Group) and those without (No-LDGroup).

To investigate the presence of neurodevelopmental indicators of risk for LDs, the neurodevelopmental outcomes at 1 and 2 years of corrected age and at 3, 4, 5, and 6 years of chronological age were analyzed comparing two groups of children on the basis of the presence or not of the LD diagnosis.

\section{Collection of Perinatal and Social Characteristics}

Basic subjects' characteristics (gender, birth weight, being adequate or small for gestational age, mode of delivery, multiple birth, duration of hospital stay, number of days on mechanical ventilation) were collected from the infants' computerized medical charts. Gestational age was based on the last menstrual period and early ultrasound examination; infants with birth weight $\geq 10$ th centile or $<10$ th centile for gestational age, according to the Fenton Growth Chart (Fenton, 2003), were classified respectively as Adequate or Small for Gestational Age (AGA/SGA). The occurrence of sepsis, necrotizing enterocolitis (NEC) of stage 2 or higher, according to the classification of Bell et al. (1978), intraventricular hemorrhage (IVH) grade 3 or higher, according to the Papile classification scheme (Papile et al., 1983), periventricular leukomalacia (PVL) of grade 2 or higher, according to de Vries et al. (1992), retinopathy of prematurity (ROP) of stage 3 or higher, according to the (Committee for the Classification of Retinopathy of Prematurity, 1984), and bronchopulmonary dysplasia (BPD), defined as oxygen supplementation at 36 weeks postmenstrual age (Jobe 


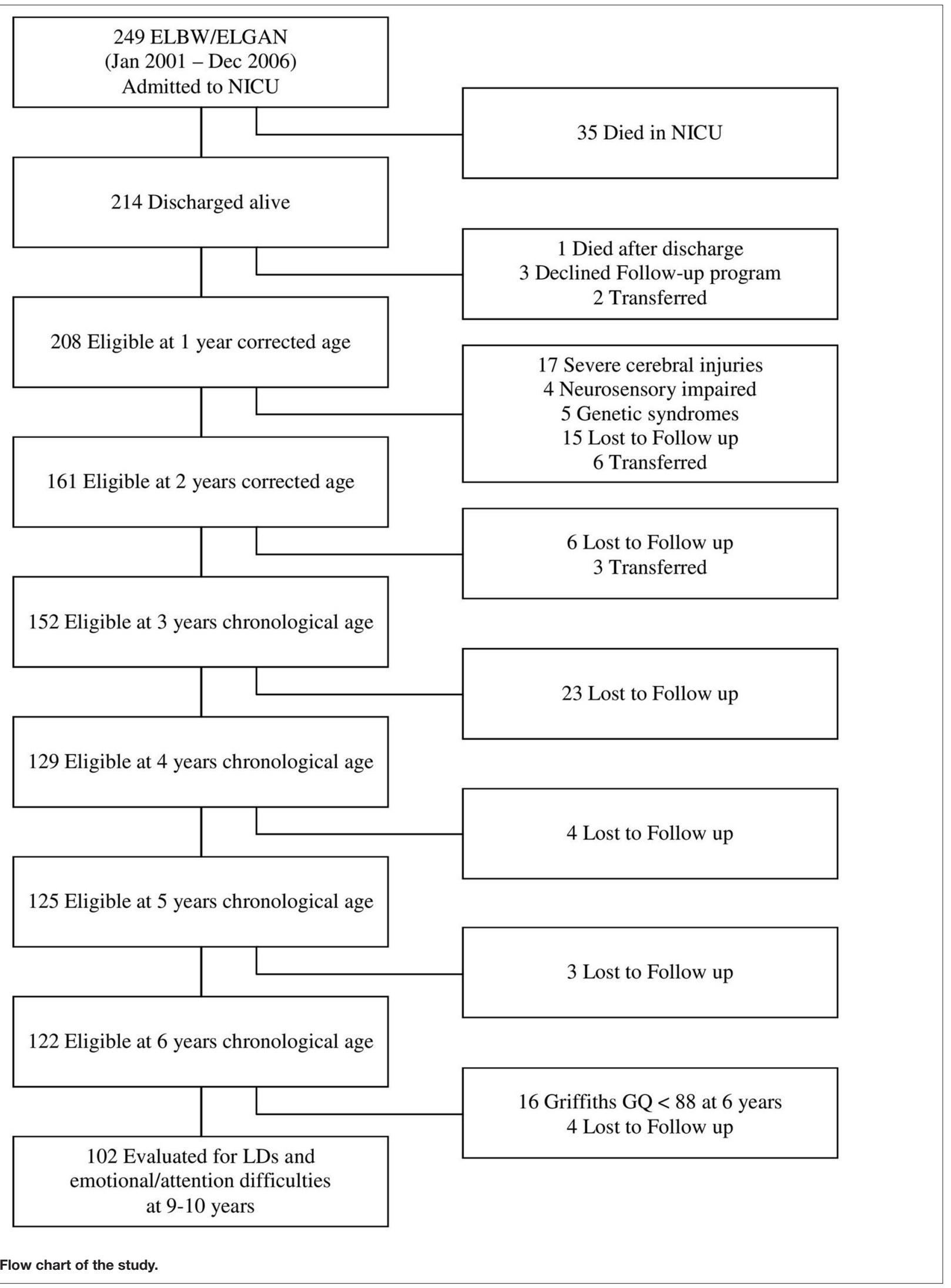

FIGURE 1 | Flow chart of the study. 
and Bancalari, 2001), were also collected. Sepsis was defined by the presence of positive blood and/or cerebrospinal fluid culture. IVH and PVL were detected by brain magnetic resonance imaging examination at 40 weeks postmenstrual age. Corrected age was calculated up to 24 months of life, from the chronological age adjusting for gestational age. Mothers' nationality and education were also recorded. Mothers' educational level was used as a measure of socioeconomic status and classified using a 3 point scale, where 1 indicates primary or intermediate school education ( $\leq 8$ years), 2 secondary school education (9-13 years) and 3 university degree ( $>13$ years).

\section{Screening of LDs and Emotional/Attention Difficulties at School Age}

In order to screen the rates of academic difficulties in our sample and the possible co-occurrence of attention and/or emotional problems a parent-report questionnaire was developed (Figure 2). Before starting the study, the questionnaire was tested with a sample of parents to clarify any doubts on item comprehension.

The questionnaire was announced by phone to the parents, when their infants were aged 9-10, by an expert psychologist that accurately explained each question and response option. All questionnaires were sent by post and parents were asked to fill-in and return them the same way.

The presence of a Learning Disability was labeled if the child had a certificated diagnosis of Learning Disability, provided by Health Services and based on the International Statistical Classification of Diseases and Related Health Problems, 10th Revision (ICD-10) criteria (WHO, 2010). Specifically, Learning Disabilities were defined as a specific and significant impairment in the development of reading/writing/computing skills, in children without neurosensory impairment or inadequate schooling, who had estimated normal IQs.

The presence of attention deficits and/or emotional disregulation, based respectively on the International Classification of Functioning, Disability and Health: Children and Youth Version (ICF-CY; WHO, 2007) definitions of Attention functions (code b140) and Emotional functions (code b152) was also investigated.

\section{Neurodevelopmental Assessment at Preschool Age}

According to our Follow-up programme, neurodevelopmental outcome was assessed by means of the Griffiths Mental Development Scales Revised (GMDS-R; ages 0-2 years) and Extended Revised (GMDS-ER; ages 2-8 years) respectively (Griffiths and Huntley, 1996; Luiz et al., 2006), administered by two trained examiners.

The Griffiths comprises a set of 5 subscales ( 6 for the extended version), with composite scores ranging from 50 to 150 . The Locomotor subscale allows the examiner to assess the child's gross motor skills. The Personal-Social subscale assesses the child proficiency in his activities of daily living, his levels of independence, as well as his ability to interact with other children. The Language subscale investigates both receptive and expressive verbal skills. The Eye and Hand Coordination subscale assesses the child's fine motor skills, visual monitoring skills, and manual dexterity. The Performance subscale investigates visuospatial skills including speed of working and precision. The Practical Reasoning subscale covers a range of skills that involve practical reasoning, such as learning numerical concepts and orientating in time and space.

The Scale yields standardized scores for each domain (mean 100, SD 16) and a composite General Quotient (mean 100, SD 12). Because normative data of the Griffiths Mental Development Scales Revised and Extended Revised are not available in our country, we referred to the 1996 and 2006 UK norms, respectively. The Italian-validated translation of the administration manuals have been used.

\section{Statistical Analyses}

The homogeneity between the two groups of children (with and without Learning Disabilities) has been verified through the confidence interval at $95 \%$ of the differences between either the means or the frequencies of the variables taken into consideration. The evolution of Griffiths scores (General Quotients and separately for each domain) was fitted with a general mixed model where age, outcome, and interaction age* outcome were introduced as fixed effect terms and child as random term. Results were expressed as least squares means $( \pm$ standard error) and differences between groups as differences between least squares means (with 95\% confidence interval of differences).

\section{RESULTS}

\section{Description of the Study Sample}

Maternal and infants' basic characteristics are shown in Table $\mathbf{1 .}$

As shown by confidence intervals, there were no significant differences between LD-Group and No-LD-Group for each of the variables considered. Nevertheless, LD-Group includes a slightly higher rate of males (though not reaching a statistical significance).

The mean ages at testing for both groups were respectively $12.3 \pm 0.5$ months and $23.9 \pm 0.5$ months of corrected age and $36.1 \pm 0.5$ months, $48.1 \pm 0.5$ months, $60.1 \pm 0.5$ months, and $72.1 \pm 0.5$ months of chronological age.

Although 18.0 and $20.8 \%$ of mothers in No-LD-Group and LD-Group respectively were not Italian, all infants attended a kindergarten or a preschool education programme and so were exposed to Italian as a primary language in their community environment.

\section{School Outcomes}

All parents who were telephonically contactable (96.0\%) at child age $9-10$ accepted to fill in the questionnaire on school outcome.

At school-age, 24 on 102 (23.5\%) of the ELBW/ELGAN children with broadly normal intelligence (Griffiths General Quotient within \pm 1 SD at 6 years) met criteria for LD in 1 or more areas. LDs in reading, written expression and arithmetic occurred respectively in 1.0, 3.9, and $4.9 \%$ of the whole study sample. Learning disabilities affecting 


\section{PARENT-REPORT QUESTIONNAIRE ON LEARNING DISABILITIES AND EMOTIONAL/ATTENTION DIFFICULTIES}

1. Did the child receive a specific diagnos is of Learning D isability by Health Services?
$\square \quad$ No
$\square \quad$ Reading Disorder
$\square \quad$ Math Disability
$\square \quad$ Disorder of Written Expression
$\square \quad$ Multiple Learning Disabilities

2. Does the child suffer of any attention difficulties (i.e. difficulties in sustaining, shifting, dividing or sharing attention; problems of concentration; distractibility)

$\begin{array}{lll}\square & 0 & \text { No } \\ \square & 1 & \text { Mild } \\ \square & 2 & \text { Moderate } \\ \square & 3 & \text { Severe } \\ \square & 4 & \text { Total }\end{array}$

3. Does the child exhibit any difficulties in the emotional regulation (i.e. difficulties in emotional regulation and expression; signs of sadness, anger, tension, anxiety; lability of emotion; flattening of affects)

$\begin{array}{lll}\square & 0 & \text { No } \\ \square & 1 & \text { Mild } \\ \square & 2 & \text { Moderate } \\ \square & 3 & \text { Severe } \\ \square & 4 & \text { Total }\end{array}$

FIGURE 2 | Parent-report questionnaire on Learning Disabilities and emotional/attention difficulties at school age.

more than 1 domain occurred in $13.7 \%$ of the children (Table 2).

In the group who met criteria for LDs (LD-Group), only $29.2 \%$ children were free from emotional or attention difficulties, compared to $69.2 \%$ children in the No-LD-Group. The prevalent difficulty in the LD-Group was in the emotional area (25.0\%) and secondary in the attention area (16.7\%). It is relevant to note that $29.2 \%$ children reported a fragility in both areas (Table 3 ). 
TABLE 1 | Maternal and infant characteristics.

\begin{tabular}{lccc}
\hline Characteristics & $\begin{array}{c}\text { No LD group } \\
(\boldsymbol{n}=\mathbf{7 8})\end{array}$ & $\begin{array}{c}\text { LD group } \\
(\boldsymbol{n}=\mathbf{2 4})\end{array}$ & $\begin{array}{c}\text { C.I. 95\% of } \\
\text { differences }\end{array}$ \\
\hline MATERNAL & & & \\
Age, years (mean) & 33.7 & 33.6 & $-2.0 ; 2.1$ \\
University degree, \% & 26.2 & 20.8 & $-14.4 ; 29.2$ \\
Italian nationality, \% & 82.0 & 79.2 & $-18.2 ; 23.9$ \\
INFANT & & & \\
Birth weight, g (mean) & 813.0 & 804.0 & $-74.0 ; 91.0$ \\
Gestational age, weeks (mean) & 27.8 & 27.7 & $-0.9 ; 1.0$ \\
Males, \% & 38.5 & 50.0 & $-13.9 ; 37.0$ \\
SGA, \% & 52.6 & 50.0 & $-23.0 ; 28.2$ \\
Multiple birth, \% & 17.9 & 16.7 & $-18.6 ; 21.2$ \\
Cesarean delivery, \% & 89.7 & 87.5 & $-15.3 ; 19.8$ \\
Sepsis, \% & 30.7 & 50.0 & $-5.8 ; 44.4$ \\
NEC stage 2-3, \% & 1.3 & 8.3 & $-7.0 ; 21.1$ \\
IVH grade 3-4, \% & 1.3 & 4.2 & $-8.2 ; 14.0$ \\
PVL, \% & 1.3 & 4.2 & $-8.2 ; 14.0$ \\
BPD, \% & 42.3 & 45.8 & $-21.9 ; 29.0$ \\
ROP grade 3-4, \% & 6.4 & 25.0 & $-2.3 ; 39.5$ \\
Days in hospital (mean) & 88.6 & 98.5 & $-5.2 ; 25.0$ \\
Days on ventilation (mean) & 9.1 & 12.4 & $-2.8 ; 9.4$ \\
\hline
\end{tabular}

TABLE 2 | LDs in reading, written expression and arithmetic in the whole sample and LD-group.

\begin{tabular}{lcc}
\hline & Whole sample $(\boldsymbol{n}=\mathbf{1 0 2})$ & LD-group $(\boldsymbol{n}=\mathbf{2 4})$ \\
\hline No LDs & $\boldsymbol{N}(\mathbf{\%})$ & $\boldsymbol{N}(\mathbf{\%})$ \\
Reading & $18(76.5)$ & $0(0.0)$ \\
Written expression & $4(1.0)$ & $1(4.2)$ \\
Arithmetic & $4(3.9)$ & $4(16.7)$ \\
More than one & $5(4.9)$ & $5(20.8)$ \\
\hline Total LDs & $14(13.7)$ & $14(58.3)$ \\
\hline
\end{tabular}

TABLE 3 | Emotional and/or attention difficulties in No-LD-group vs. LD-group.

\begin{tabular}{lcc}
\hline & No-LD-group $(\boldsymbol{n}=\mathbf{7 8})$ & LD-group $(\boldsymbol{n}=\mathbf{2 4})$ \\
& $\boldsymbol{N}$ (\%) & $\boldsymbol{N}$ (\%) \\
\hline No difficulties & $54(69.2)$ & $7(29.2)$ \\
Emotional difficulties (only) & $12(15.4)$ & $6(25.0)$ \\
Attention difficulties (only) & $8(10.3)$ & $4(16.7)$ \\
Both difficulties & $4(5.1)$ & $7(29.2)$ \\
\hline
\end{tabular}

\section{Preschool Outcomes}

Table 4 shows the differences in mean scores (estimated with a general mixed model) between LD-Group vs. No-LD-Group Griffiths' General Quotients and Subquotients at 1 and 2 years of corrected age, and at 3 to 6 years of chronological age.
The mean General Quotients of the two groups show the highest difference at 2 years of corrected age (8.0 points of difference), with the LD Group standing between a low-average and a below-the-mean level. At later ages the discrepancy tends to decrease to 2.8 points ( 5 years) and 2.2 points ( 6 years), though remaining statistically significant. An overall improvement can be observed in the LD-Group General Quotients, while No-LDGroup mean scores remain more stable.

Considering the differences between the two groups' mean subquotients, the 2 and 5-years assessments are the most noteworthy regarding both the variety of neurodevelopmental domains and the wideness of the score differences. Conversely, at the other assessment stages the discrepancy between the two groups' subquotients is more subtle.

At 2 years of corrected age the largest gap between the two groups emerges in the Language (11.6 points of difference), and the Locomotor ( 8.7 points) subscales, while at 5 years of chronological age the widest differences are in the Performance (5.5 points), Practical Reasoning (4.0) and Personal-Social (3.0) subscales.

A quite stable significant difference in the Eye and Hand Coordination subscale emerges both at 1 year of corrected age (5.8 points of difference) and at 3 years ( 3.8 points), 4 years ( 4.2 points), and 6 years (2.9) of chronological age.

\section{DISCUSSION}

\section{Outcome at School Age}

Our study shows that $23.5 \%$ of our ELBW/ELGAN children with broadly normal intelligence met criteria for $\mathrm{LD}$ with a prevalence of Learning Disabilities in multiple domains (13.7\%).

Attention and/or emotional difficulties were found in $70.8 \%$ of children with LDs, but only in $30.8 \%$ of children without LDs.

Compared to the last reports of the Italian Ministry of Education, University and Research referring to 2011/2012 academic years (MIUR, 2013), the incidence of LDs in our sample is significantly higher than the overall regional population (23.5 vs. $2.0 \%$ ). This is confirmed by other authors, highlighting that ELBW children are more likely to show difficulties in basic academic skills and multiple learning domains compared to children born at term or with weight $>2500 \mathrm{~g}$ (Salt and Redshaw, 2006; Wocadlo and Rieger, 2006).

Our rates of LDs are comparable to those of Johnson et al. (2011). The authors investigated the academic attainment at 11 years of a cohort of ELBW infants born $<26$ weeks gestation free from severe neurosensory and cognitive impairment and found $27.0 \%$ LDs (vs. $23.5 \%$ of our study cohort). The high concordance with Johnson's findings is probably due to the exclusion of severely impaired children from their study, which was our main exclusion criteria too.

On the contrary, our rates are much lower than those reported by the EPICure study group (Johnson et al., 2009; 50.0\%) and by Anderson and Doyle (2008; 36.0\%). This difference may arise from the characteristics of the sample as these studies included extremely premature children ( $<26$ weeks Gestational age and/or $<750$ g Birth weight) with severe neurosensitive and cognitive impairment (as previously defined) at 11 years. 
TABLE 4 | Estimated Griffiths mean scores in No-LD-Group vs. LD-Group.

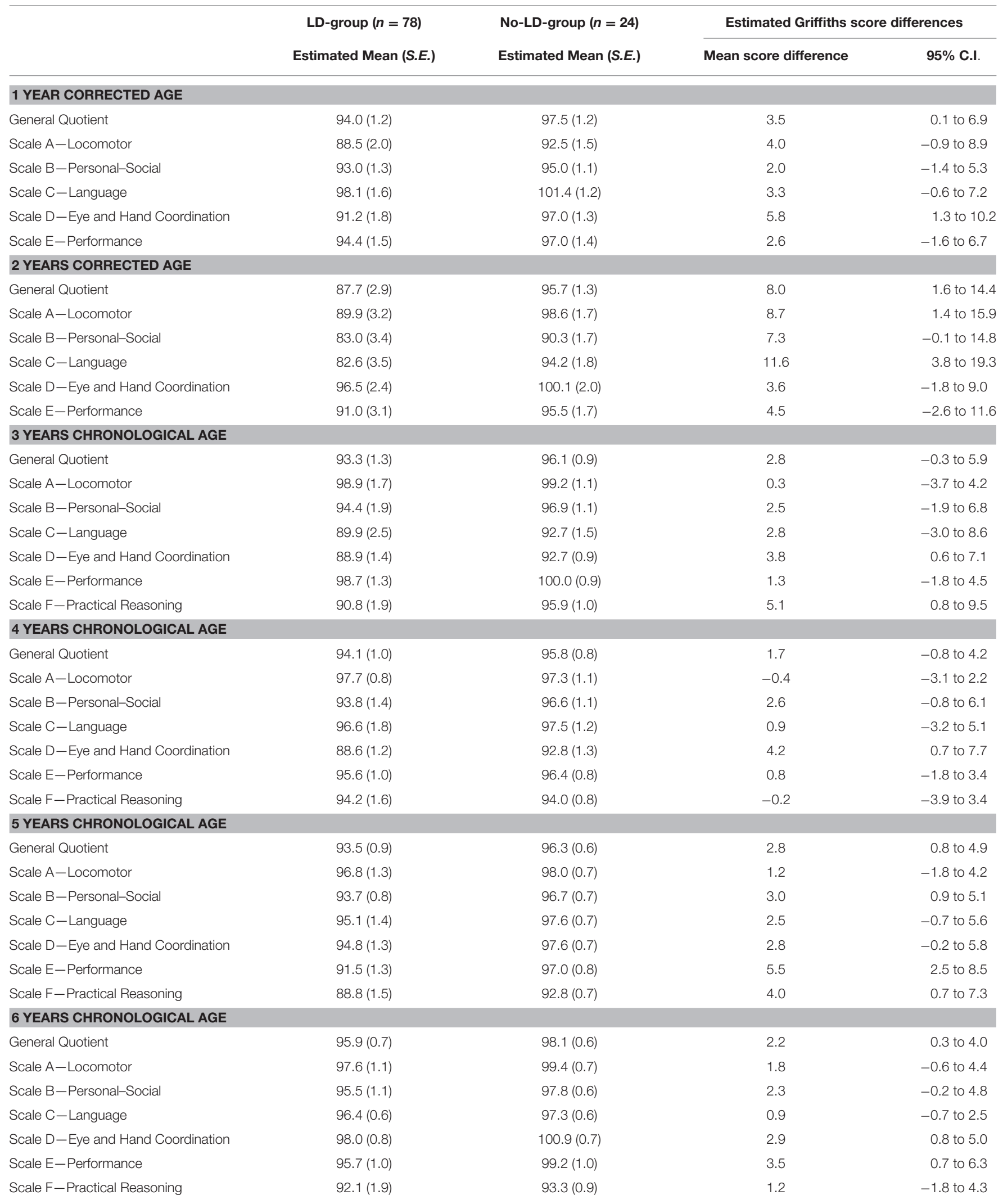




\section{Neurodevelopmental Profiles at Preschool Age}

The neurodevelopmental profiles at preschool ages showed that the 2 years of corrected age and the 5 years of chronological age assessment stages were the most effective in discriminating between the LD-Group and No-LD-Group outcomes. Children with LDs actually showed significantly lower mean scores in Locomotor and Language subscales at 2 years of corrected age and both in Personal-Social and in Performance and Practical Reasoning subscales at 5 years of chronological age.

Early motor experimentation, enabling the child to discover the environment and take contact with objects and persons, enhances the maturation and organization of higher cognitive functions. Consequently, the low performance shown by the LD-Group in the Locomotor subscale at 2 years of corrected age might lead to a poorly integrated mental representation and organization of spatial experiences and objects. Indeed, in literature there is evidence of a strong association between early motor development and later intellectual functions within the normal population (Murray et al., 2006).

Besides, Walle and Campos (2014) demonstrated that walking onset is related to infant language development. Thus, we speculate that also the poor performance of the LD-Group in the Language subscale might be associated to a poor desire for experimentation, limiting the expansion of verbal expressive skills.

At 5 years of chronological age the LD-Group showed significantly lower scores in the Personal-Social, Performance and Practical Reasoning subscales.

For the LD-Group, the low scores in the Personal-Social subscale reveal a lack of personal independency and a poor motivation in differentiating from their caregivers.

The frequent co-occurrence of LDs and emotional deficits in our sample supports the hypothesis of an emotional immaturity in the LD-Group. Follow-up studies confirm that behavioral and socio-emotional impairments may negatively affect cognitive functions and academic achievements in preterms (AarnoudseMoens et al., 2009; Pugliese et al., 2013).

Since our sample included only children with broadly average intelligence, the discrepancy between the LD-Group and No-LDGroup in the Performance and Practical Reasoning Subquotients at 5 years seems not to be related to a cognitive impairment but mostly to a lack of flexibility in problem solving strategies and to a poor ability in managing everyday situations. This consistent with previous studies with very preterm or ELBW children, reporting impairments across a range of executive processes including planning and organizational ability, generation of new ideas and strategies and mental flexibility (Anderson et al., 2004).

As far as the Eye and Hand Coordination subscale is concerned, we speculate that the low mean scores shown by the LD-Group along all the study period may be related to an unsuitable coordination between eyes and hands but may also be mediated by an attention deficit. Several literature studies confirm that minor motor disabilities persist in survivors of preterm birth and that they often co-exist with behavioral deficits. Specifically, attention seems to be an area of specific weakness for preterm children (Foulder-Hughes and Cooke, 2003; Feder et al., 2005; Mulder et al., 2009). The high rate of attention difficulties reported at school age by this group of children strengthens our hypothesis.

\section{LIMITS OF OUR STUDY}

The major limit of our study is the lack of a direct assessment of LDs at school age. Relying exclusively on the presence of a LD certification may raise doubts on the possible presence of undiagnosed LDs who didn't reach Health Services because not identified as suspected cases by teachers. However, the Italian legislation regarding Learning Disabilities requires a screening using standardized tests by the end of the second school year. Therefore, we are confident that all the children enrolled in our study who showed any academic difficulties have been correctly identified and addressed to specialists to receive a LD diagnosis.

\section{CONCLUSIONS}

Our findings indicate that children born ELBW are particularly vulnerable to learning disabilities at school age associated with attention and emotional difficulties. Our findings suggest that among the early developmental indicators of adverse school outcome there is a poor motor experimentation, language delay and personal-social immaturity. The lack of cognitive flexibility and the poor ability to manage practical situations at preschool age also interfere with intellectual functioning, negatively affecting the academic attainment.

These results might be useful to established prevention and monitoring interventions and to facilitate the collaboration between the various figures involved in the child's care (healthcare professionals, teachers and families.

Focusing on these early indicators of risk for adverse school outcome is crucial to ensure an adequate support for the child, maximizing his/her abilities and assisting the transition to school.

\section{AUTHOR CONTRIBUTIONS}

CS, LG, and MG conceptualized and designed the study, interpreted the clinical data of follow up, drafted the initial manuscript, and critically reviewed the manuscript. OP, $\mathrm{AM}$, and SG designed the data collection instruments and critically reviewed the manuscript. IC and SM carried out the initial analyses, reviewed, and revised the manuscript. FM interpreted the clinical data of follow up and critically reviewed the manuscript. All authors read and approved the final manuscript and agree to be accountable for the content of the work.

\section{ACKNOWLEDGMENTS}

We are grateful to the children and families who participated in the study. Thank you also to the nurses of the preterms' Follow-up Clinic for their contribution. A special thanks to 
Matteo Porro, MD, Maura Ravasi, Psychologist, Marta Macchi, MD, Andrea Frigerio Neuropsychomotrician, and Paola Ajmone, $\mathrm{MD}$, members of the preterms' follow-up research group at

\section{REFERENCES}

Aarnoudse-Moens, C. S., Weisglas-Kuperus, N., van Goudoever, J. B., and Oosterlaan, J. (2009). Meta-analysis of neurobehavioral outcomes in very preterm and/or very low birth weight children. Pediatrics $124,717-728$. doi: 10.1542/peds.2008-2816

Anderson, P. J., and Doyle, L. W. (2008). Cognitive and educational deficits in children born extremely preterm. Semin. Perinatol. 32, 51-58. doi: 10.1053/j.semperi.2007.12.009

Anderson, P. J., and Doyle, L. W., Victorian Infant Collaborative Study Group (2004). Executive functioning in school-aged children who were born very preterm or with extremely low birth weight in the 1990s. Pediatrics 114, 50-57. doi: $10.1542 /$ peds.114.1.50

Bell, M. J., Ternberg, J. L., Feigin, R. D., Keating, J. P., Marshall, R., Barton, L., et al. (1978). Neonatal necrotizing enterocolitis. Therapeutic decisions based upon clinical staging. Ann. Surg. 187, 1-7. doi: 10.1097/00000658-19780100000001

Bowen, J. R., Gibson, F. L., Leslie, G. I., Arnold, J. D., Ma, P. J., and Starte, D. R. (1996). Predictive value of the Griffiths assessment in extremely low birthweight infants. J. Paediatr. Child Health 32, 25-30. doi: 10.1111/j.14401754.1996.tb01536.x

Committee for the Classification of Retinopathy of Prematurity (1984). An international classification of retinopathy of prematurity. Pediatrics 74, 127-133.

de Vries, L. S., Eken, P., and Dubowitz, L. M. (1992). The spectrum of leukomalacia using cranial ultrasound. Behav. Brain Res. 49, 1-6. doi: 10.1016/S01664328(05)80189-5

Doyle, L. W., Roberts, G., Anderson, P. J., and Victorian Infant Collaborative Study Group (2011). Changing long-term outcomes for infants 500-999 g birth weight in Victoria, 1979-2005. Arch. Dis. Child. Fetal Neonatal Ed. 96, F443-F447. doi: 10.1136/adc.2010.200576

Farooqi, A., Hägglöf, B., and Serenius, F. (2013). Behaviours related to executive functions and learning skills at 11 years of age after extremely preterm birth: a Swedish national prospective follow-up study. Acta Paediatr 102, 625-634. doi: 10.1111/apa.12219

Feder, K. P., Majnemer, A., Bourbonnais, D., Platt, R., Blayney, M., and Synnes, A. (2005). Handwriting performance in preterm children compared with term peers at age 6 to 7 years. Dev. Med. Child Neurol. 47, 163-170. doi: $10.1017 /$ S0012162205000307

Fenton, T. R. (2003). A new growth chart for preterm babies: Babson and Benda's chart updated with recent data and a new format. BMC Pediatr. 3, 13-23. doi: 10.1186/1471-2431-3-13

Foulder-Hughes, L. A., and Cooke, R. W. (2003). Motor, cognitive, and behavioural disorders in children born very preterm. Dev. Med. Child Neurol. 45, 97-103. doi: 10.1111/j.1469-8749.2003.tb00912.x

Griffiths, R., and Huntley, M. (1996). The Griffiths Mental Development ScalesRevised Manual: From Birth to 2 Years. Transl. by F. M. Battaglia and M. Savoini in Italian. High Wycombe; Firenze: ARICD; Giunti O.S.

Grunau, R. E., Whitfield, M. F., and Davis, C. (2002). Pattern of learning disabilities in children with extremely low birth weight and broadly average intelligence. Arch. Pediatr. Adolesc. Med. 156, 615-620. doi: 10.1001/archpedi.156. 6.615

Jobe, A. H., and Bancalari, E. (2001). Bronchopulmonary dysplasia. Am. J. Respir. Crit. Care Med. 163, 1723-1729. doi: 10.1164/ajrccm.163.7.20 11060

Johnson, S., Hennessy, E., Smith, R., Trikic, R., Wolke, D., and Marlow, N. (2009). Academic attainment and special educational needs in extremely preterm children at 11 years of age: the EPICure study. Arch. Dis. Child. Fetal Neonatal Ed. 94, F283-F289. doi: 10.1136/adc.2008. 152793
NICU, Department of Clinical Sciences and Community Health, for their competent and experienced assistance throughout the research.
Johnson, S., Wolke, D., Hennessy, E., and Marlow, N. (2011). Educational outcomes in extremely preterm children: neuropsychological correlates and predictors of attainment. Dev. Neuropsychol. 36, 74-95. doi: 10.1080/87565641.2011.540541

Latini, G., De Felice, C., Giannuzzi, R., and Del Vecchio, A. (2013). Survival rate and prevalence of bronchopulmonary dysplasia in extremely low birth weight infants. Early Hum. Dev. 89, S69-S73. doi: 10.1016/S0378-3782(13) 70020-3

Litt, J. S., Taylor, H. G., Margevicius, S., Schluchter, M., Andreias, L., and Hack, M. (2012). Academic achievement of adolescents born with extremely low birth weight. Acta Paediatr. 101, 1240-1245. doi: 10.1111/j.1651-2227.2012. 02790.x

Lobo, M. A., and Galloway, J. C. (2013). Assessment and stability of early learning abilities in preterm and full-term infants across the first two years of life. Res. Dev. Disabil. 34, 1721-1730. doi: 10.1016/j.ridd.2013. 02.010

Luiz, D. M., Barnard, A., Knoessen, N. P., Kotras, N., Horrocks, S., McAlinden, P., et al. (2006). The Griffiths Mental Development Scales-Extended Revised: 2 to 8 Years Administration Manual. Transl. by C. Cianchetti and G. S. Fancello in Italian. Oxford, UK; Firenze: Hogrefe; Giunti O.S.

Marlow, N., Wolke, D., Bracewell, M. D., Samara, M., and EPICure Study Group (2005). Neurologic and developmental disability at six years of age after extremely preterm birth. N. Engl. J. Med. 352, 9-19. doi: 10.1056/NEJMoa041367

MIUR (2013). Alunni con Disturbi Specifici di Apprendimento. Direzione Generale per gli Studi, la Statistica e i Sistemi Informativi. Rilevazioni a.s. 2010-2012.

Msall, M. E. (2012). Academic achievement after extreme prematurity: optimizing outcomes for vulnerable children in times of uncertainty. Acta Paediatr. 101, 1196-1197. doi: 10.1111/apa.12038

Mulder, H., Pitchford, N. J., Hagger, M. S., and Marlow, N. (2009). Development of executive function and attention in preterm children: a systematic review. Dev. Neuropsychol. 34, 393-421. doi: 10.1080/875656409029 64524

Murray, G. K., Veijola, J., Moilanen, K., Miettunen, J., Glahn, D. C., Cannon, T. D., et al. (2006). Infant motor development is associated with adult cognitive categorisation in a longitudinal birth cohort study. J. Child Psychol. Psychiatry 47, 25-29. doi: 10.1111/j.1469-7610.2005. 01450.x

Orton, J., Spittle, A., Doyle, L., Anderson, P., and Boyd, R. (2009). Do early intervention programmes improve cognitive and motor outcomes for preterm infants after discharge? A systematic review. Dev. Med. Child Neurol. 51, 851-859. doi: 10.1111/j.1469-8749.2009. 03414.x

Papile, L. A., Munsick-Bruno, G., and Schaefer, A. (1983). Relationship of cerebral intra-ventricular hemorrhage and early childhood neurologic handicaps. J. Pediatr. 103, 273-277. doi: 10.1016/S0022-3476(83) 80366-7

Pugliese, M., Rossi, C., Guidotti, I., Gallo, C., Della Casa, E., Bertoncelli, N., et al. (2013). Preterm birth and developmental problems in infancy and preschool age Part II: cognitive, neuropsychological and behavioural outcomes. J. Matern. Fetal Neonatal Med. 26, 1653-1657. doi: 10.3109/14767058.2013. 794205

Salt, A., and Redshaw, M. (2006). Neurodevelopmental follow-up after preterm birth: follow up after two years. Early Hum. Dev. 82, 185-197. doi: 10.1016/j.earlhumdev.2005.12.015

Simms, V., Cragg, L., Gilmore, C., Marlow, N., and Johnson, S. (2013). Mathematics difficulties in children born very preterm: current research and future directions. A review. Arch. Dis. Child. Fetal Neonatal Ed. 98, F457-F463. doi: 10.1136/archdischild-2013-303777 
Sutcliffe, A. G., Soo, A., and Barnes, J. (2010). Predictive value of developmental testing in the second year for cognitive development at five years of age. Pediatr. Rep. 2, 48-50. doi: 10.4081/pr.2010.e15

Taylor, H. G., Klein, N., Anselmo, M. G., Minich, N., Espy, K. A., and Hack, M. (2011). Learning problems in kindergarten students with extremely preterm birth. Arch. Pediatr. Adolesc. Med. 165, 819-825. doi: 10.1001/archpediatrics.2011.137

Walle, E. A., and Campos, J. J. (2014). Infant language development is related to the acquisition of walking. Dev. Psychol. 50, 336-348. doi: 10.1037/a0033238

Wocadlo, C., and Rieger, I. (2006). Educational and therapeutic resource dependency at early school-age in children who were born very preterm. Early Hum. Dev. 82, 29-37. doi: 10.1016/j.earlhumdev.2005.06.005

World Health Organization (2007). International Classification of Functioning, Disability and Health: Children and Youth Version (ICF-CY). Geneva: WHO Press.
World Health Organization (2010). International Statistical Classification of Diseases and Related Health Problems, 10th Revision (ICD-10). Geneva: WHO Press.

Conflict of Interest Statement: The authors declare that the research was conducted in the absence of any commercial or financial relationships that could be construed as a potential conflict of interest.

Copyright (c) 2016 Squarza, Picciolini, Gardon, Gianni, Murru, Gangi, Cortinovis, Milani and Mosca. This is an open-access article distributed under the terms of the Creative Commons Attribution License (CC BY). The use, distribution or reproduction in other forums is permitted, provided the original author(s) or licensor are credited and that the original publication in this journal is cited, in accordance with accepted academic practice. No use, distribution or reproduction is permitted which does not comply with these terms. 